Marquette University

e-Publications@Marquette

College of Nursing Faculty Research and

Publications

Nursing, College of

$1-1-2008$

\title{
Teaching Social Justice Using a Pedagogy of Engagement
}

Ruth Belknap

Marquette University, ruth.belknap@marquette.edu

Accepted version. Nurse Educator, Vol.33, No. 1 (January/February 2008). DOI. (C) 2008 Lippincott Williams and Wilkins, Inc. Used with permission. 


\title{
Teaching Social Justice Using a Pedagogy of Engagement
}

Ruth Ann Belknap, PhD, APRN, BC

\begin{abstract}
Teaching an undergraduate level diversity course with a health focus requires specific teaching methods. A pedagogy of engagement provides an effective strategy for exploring issues of race, class, gender, and structural inequalities that underlie health disparities. Engagement learning enhances understanding of theories of oppression and liberation presented in the course and highlights social justice issues.
\end{abstract}

Culture and Health is a course offered within the College of Nursing at a Midwestern Jesuit University. Promotion of justice is at the center of the university's mission. The course fulfills a university core course requirement for diversity studies and is open to all students. It is required for undergraduate nursing students. A typical class contains freshman and sophomore students from nursing and other health science majors as well as students from a variety of non-health-related majors. The student mix provides differing perspectives that enhance classroom discussion and learning.

The course description focuses on the cultural aspects of the course and mentions developing an appreciation for diversity. However, because this course meets a university diversity requirement, it also has objectives related to that requirement (Figure 1).

Students are often surprised when during the first class session, it becomes clear that this is not a course about "interesting oddities" associated with "other" cultures. Instead this course lays the foundation for culturally competent care by learning about cultures. I explain that to begin to understand issues of culture and health and their relationship to social structures, it is necessary to first look at ourselves, our biases, and our presuppositions. This includes examination of social inequities and our place in sustaining and confronting them. My challenge as the faculty is to balance the bad news of health disparities held in place by structural inequalities with the optimism that, with focused effort, things can indeed change.

\section{Social Justice and Engagement Pedagogy}

Students socialized in the United States of America identify with a market justice perspective. Market justice emphasizes individual responsibility as the basis for the distribution 
of burdens and benefits and minimizes collective obligation. ${ }^{1}$ Therefore, it is helpful at the beginning of the course to make a case for the relevance of a social justice perspective. This is accomplished in 2 ways: by presenting social justice as the philosophy that frames the work of public health and as an integral part of Jesuit education.

Social justice argues that significant factors in society (ie, racism, classism, and sexism) impede fair distribution of benefits and burdens and that collective action is necessary to neutralize or overcome these impediments. ${ }^{1}$ A social justice perspective is critical in meeting a core diversity objective (see Figure 1, objective 2) and foundational to addressing health disparities.

A pedagogy of engagement promotes knowledge and process learning occurring together. Mestre ${ }^{2}$ succinctly outlined classroom attributes of pedagogies of engagement. These include student self-responsibility as learners, collaborative work in constructing knowledge, construction of coherent arguments to support answers, and classroom time spent on refining conceptual understanding. Engagement in this course occurs on many levels: with other learners during class discussion, with the community, and with cultures other than the student's own.

\section{Launching the Course}

I have found 3 components instrumental for engagement to occur in the class room. Successful classroom engagement is facilitated by addressing physical space, establishing class guidelines, and being clear about student preparation.

\section{Physical Space Considerations}

Engagement requires connection and relationship among all who are present in the classroom. Establishing a safe space for discussion where students and professor can come together and function as a community of learners is foundational. Therefore, the first class is opened by reflecting on the physical arrangement of the classroom. The ideal space is a room where we can all sit in a circle. However, I am often faced with seats bolted to the floor in rows or movable chairs in a room too small to accommodate a circle large enough for all students. So I engage the class in a discussion of physical space and power relationships conveyed by spatial positions. Together we establish a space where learners face each other, not the professor. In lecture rooms with immovable seats, students might leave spaces in the middle of the room open and turn during discussion to face each other. In a room too small to arrange chairs in a circle, chairs may end up in a sort of double horseshoe or semicircles facing each 
other. Physical arrangement is critical. Developing a community where relational learning can take place cannot occur when students look only at the backs of the heads of students in front of them.

\section{Guidelines for Discussion}

As I briefly introduce the topics we will be discussing, such as race and class, I indicate that this type of learning often occurs through sharing one's experience and personal reflections. Following the method described by Adams et $\mathrm{al}^{3}{ }^{3} \mathrm{I}$ ask students what guidelines for discussion are needed for creating a safe space where sharing can occur. As students make suggestions, I write them on the board. I ask students to clarify the meaning of specific suggestions with behavioral examples. Behavioral definitions of respect might include not having side conversations and allowing time for others to speak. Once student ideas have stopped flowing, we review the list and come to a consensus about which guidelines to adopt. Universally, respect and confidentiality make the list. Typically all of the recommendations are accepted.

\section{Student Preparation}

Student preparation for discussion is the third necessary component. Requesting students to come to class prepared to discuss the assigned reading is usually inadequate incentive for students to actually do so. I have found quizzes, announced or unannounced, also have little impact on the quality of student discussion. In my experience, assigning a preclass writing exercise that requires the students to read and begin to synthesize concepts does elevate the level of discussion. I ask the students to respond to the reading or connect the reading with their life experiences in one type-written page submitted at the beginning of class

(Figure 2). Students receive class participation credit for turning in satisfactory papers. Satisfactory papers are those that provide evidence the material was read and demonstrate effort toward the requested synthesis.

\section{Sequencing of Course Concepts}

We begin with discussions of key concepts (race, class, gender), and soon their interrelatedness becomes apparent. The relationships among the key concepts are reinforced frequently during the early weeks of class. The first few times students introduce examples where any 2 of these factors interact, I note the connection by saying, "Terrific example." Then I write race/class/gender/culture on the black board as a reminder that all are functioning together. After an initial exploration of these concepts, theories of oppression, racism, classism, sexism, 
and issues of healthcare disparities are added. Students typically show signs of frustration at this point. As the teacher, I have introduced many social problems and have not provided any solutions. This is the perfect opportunity to introduce a conceptual model of liberation. ${ }^{4}$ Once students have developed a working understanding of these foundational theories and can identify examples from readings and media shown in class, we are ready to begin health-focused cultural explorations.

\section{Teaching Strategies for Specific Concepts}

The goal of synthesis of course content with life experience begins in the classroom. I have found the following strategies helpful for initiating dialogue and deepening understanding.

\section{Social Class}

To begin the exploration of social class, I often use current news articles. The book Class Matters, by authors at The New York Times, ${ }^{5}$ provides useful narratives that highlight social class issues, conflicts, and struggles. One particular story makes a useful case study. In it, a comparison is made of treatment after a myocardial infarction of persons from differing socioeconomic classes. The causes of heart disease and preventative measures prevalent in the media are familiar to students. Students are asked to identify obstacles to the recovery of a woman from a working class background and which obstacles they believe are within her control. The usual list of behaviors generally understood to be within her control emerge, such as changing her diet and exercising. Students are then challenged to examine these behaviors in the context of the patient's life. It soon becomes clear that many of her apparently unhealthy "choices" are determined by her lack of resources, culture, and life situation.

\section{Race and Racism}

Discussing social class may be a new experience, ;nonetheless, students are intrigued and enter the discussion readily. Discussion race within a large group, however, is unfamiliar and uncomfortable territory for most students. We start with a definition of race. The Public Broadcasting Services Web site, Race the Power of an Illusion (Figure 3), is used as a preclass activity and starting point for class discussion. This Web site offers a variety of activities that explain how "race" is more than a set of biological factors-it is a socially constructed concept. Having all had the same preclass assignment, students are quite willing to enter a discussion focused on comparing their thoughts about race before and after completing the activity. After this initial step, we move into an area students are more hesitant to address, racism. Students

\section{Belknap}


read the metaphoric Gardener's Tale. ${ }^{6}$ Three forms of racism are presented in this article: personally mediated, institutionalized, and internalized. Students immediately recognize personally mediated racism as "racist behavior" and as "wrong." At first this recognition inhibits open discussion. Some students also have difficulty acknowledging that this type of racism continues to be common in our society. The concept of institutionalized racism is new to most students. Students question how this is possible; surely this type of discrimination ended after the civil rights movement in the 1960s. Students from minority groups may not know this concept by name. However, they are more likely to readily recognize and identify the effects of institutionalized racism. Utilizing media that portray college students discussing race (such as the DVDs What's Race Got to Do With It or Skin Deep; Figure 2) is very useful in initiating discussion. Students are comfortable reacting to the students shown in the video. Once a few students have responded to the media presentation, a gentle urging may be all that is needed to get students to respond to each other.

\section{Oppression and Liberation}

Oppression and liberation are not terms used in everyday discourse by undergraduate college students. However, they are terms central to social justice teaching. Young ${ }^{7}$ describes the traditional use of the word oppression as referring to the acts of "tyranny by a ruling group." She argues that the modern usage of the word by those involved in social justice movements refers to constraints on groups of people that have negative consequences, yet go unquestioned because they are imbedded in the norms of society. Alone, this definition has limited use in assisting students to understand structural inequalities. However, Young combines this with an explication of 5 faces of oppression: exploitation, marginalization, powerlessness, cultural imperialism, and violence. The definitions of the concepts and examples provided are well understood by the students, thus giving students tools and language need to explain social inequities.

The "Cycle of Liberation" 4 is used to provide a conceptual model for visualizing the process of social change. More importantly, it provides students with a road map that enables them to identify ways they can engage in social change. This model describes critical transformation as a 7-stage process of liberation resulting in social change. The stages are as follows: waking up, getting ready, reaching out, building community, coalescing, creating change, and maintaining.

The first step we make toward connecting the processes of oppression and liberation to a life situation takes place in the classroom. We view the documentary, The Forgotten 
Americans (Figure 2). This film vividly describes life in the Colonias in the United States along the Mexican border. It provides ample examples of the faces of oppression. Exploitation is depicted throughout the video as those who have purchased lots in the colonias wait for basic infrastructure, such as roads and water lines, which is promised but never constructed. Individual and community actions that successfully oppose structural inequalities are seen in the lives and stories of community organizers who are eventually successful in bringing a road into their community. The film serves 2 purposes. It provides a venue for connecting course concepts with a real-life situation, and it provides a compelling description of social injustice occurring in the United States.

The next step in connecting course concepts with real-life situations occurs in the service learning (SL) experience (described below). All SL sites have clients who are experiencing oppression, and all of the sites are places where change occurs through liberation processes. During focused class discussions, students are asked to reflect on their experiences in the context of oppression and liberation theories. Shifts in student understanding are evident in the written synthesis paper at the end of the course. For example, students in after-school programs in an urban environment where many children live in poverty have commented on how they assumed that most white teenagers go to college because they try harder (than minorities). However, after the SL experience, students describe an awareness of how their education and childhood environment greatly facilitated their readiness for college.

\section{Engagement Strategies for Cultural Exploration}

Media, literature from the culture, and SL activities are used for cultural engagement. The first strategy is a small group project in which students prepare a class presentation about a specific culture. Guidelines for the presentation require the students to present the culture in a way that allows the class to feel they have experienced the culture. Each group chooses a book, either a memoir or an autobiography, as an organizing framework for the presentation. The presentation synthesizes course concepts with examples from the book as well as from other sources. Typically, students are quite creative in this process. A presentation might include combinations of PowerPoint slides, online video clips, food, photos, and poetry. One group invited a traditional dance team to perform during the class.

The second engagement strategy is SL. Service learning is a university program where students combine community service with classroom theory. The aims of the program include enriching classroom learning, facilitating personal growth, and building community with partner agencies (http://www.marquette.edu/service-learning/). In this course, students are required to

\section{Belknap}


do approximately 2 hours of service per week in the community. Students choose from a variety of experiences including tutoring, after-school programs, assisting in food distribution or meal programs, and participating in activities with persons who have mental or physical disabilities. Students are required to choose a setting that includes clients from backgrounds that are different, culturally or socioeconomically, from the student's. The University is well known for its outstanding SL program, placing about 1,100 students in the community each semester.

\section{Conclusion}

Integration of students' understanding of course concepts occurs during class discussion, in the creation of the group presentation, and in a final synthesis paper about the SL experience. Evaluation of student work at the end of the semester indicated that all students were able to integrate the concepts with life experience, some at a more sophisticated level than others.

Overall, anonymous student evaluations of the teaching methods used in the course are positive. Students have an opportunity to evaluate all assignments, activities, and media. One unexpected finding was the positive evaluation of the preclass writing assignment. I had anticipated that students might evaluate this activity as unnecessary and burdensome. However, most students indicated they agreed or strongly agreed with the statement, "The assignment contributed to my learning." Students also respond to a series of open-ended questions about the course. When asked, "In what ways has this course influenced you?" the most frequent response is, "it opened my eyes." Other specific comments included the following:

- I was aware of these major issues but never had the opportunity to discuss, research, and read about them.

- It made me realize the disparities that still exist and where I fit in with it all.

- I realize I have the ability to help.

When confronted with harsh social problems, students want to know the causes and solutions. There are no easy answers. The problems are complex and the solutions are evolving. I have found that this particular combination of strategies provides students with skills for exploration as well as tools for social change.

\section{Notes}

- Author Affiliation: Assistant Professor, College of Nursing, Marquette University, Milwaukee, Wisconsin.

7 Belknap 
- Correspondence: College of Nursing, Marquette University, PO Box 1881, Milwaukee, WI 53201-1881 (ruth.belknap@marquette.edu).

\section{References}

1. Turnock BJ. Public Health: What it is and how it works. 3rd ed. Boston: Jones and Bartlett; 2004.

2. Mestre JP. Transfer of Learning From a Modern Multidisciplinary Perspective. Greenwich, CT: Information Age Publishing; 2005.

3. Adams M, Bell LA, Griffin P. Teaching for Diversity and Social Justice: A Source-book. New York: Routledge; 1997.

4. Harro B. The cycle of liberation. In: Adams M, ed. Readings for Diversity and Social Justice. London: Routledge; 2000: 463-469.

5. Class Matters. 1st ed. New York: Times Books; 2005.

6. Jones CP. Levels of racism: a theoretical framework and a gardener's tale. Am J Public Health. 2000;90(8):1212-1215.

7. Young IM. Five faces of oppression. In: Adams M, ed. Readings for Diversity and Social Justice. London: Routledge; 2000:35-49.

8. Tatum BD. Why Are All the Black Kids Sitting Together in the Cafeteria? And Other Conversations on Race. New York: Basic Books; 2003. 
Appendix

Figure 1. Course information.

\section{Course Description}

Cultural perspective of concepts of health and illness, including the relationship of healthcare behaviors and beliefs to culture and social structure. Foster an appreciation for human diversity related to culture and health.

\section{Objectlves for dlversity core courses}

Identify differences and similarities in communication, values, practices, and beliefs between one's own culture and other cultures.

Explain how categories of human diversity (such as race, gender, ethnicity, and disability) influence personal identities and can create structural and institutional inequity.

Critically reflect upon one's personal and cultural presuppositions and how these affect one's values and relationships.

Figure 2. Examples of preclass writing assignments on "Race and Racism."

\section{Assignment 1}

What is the relationship between "white privilege" (as described by Tatum in Why Are All the Black Kids Sitting Together in the Cafeteria?) ${ }^{8}$ and "institutionalized racism" (as described in the article, A Gardner's Tale). ${ }^{6}$

In what ways do whites in America benefit (knowingly and unknowingly) from institutionalized racism?

\section{Assignment 2}

Apply your life to the concepts in chapter 2, of Tatum's Why Are All the Black Kids Sitting Together in the Cafeteria? Describe one insight you gained conceming dominant and subordinate groups.

According to Tatum, what are the 2 developmental tasks necessary for whites to achieve a healthy sense of white identity? Which do you think is most challenging and why? 
Figure 3. Resources.

Web

Race the Power of an I/lusion http://www.pbs.org/race/000 General/000 00-Home.htm

Tour Poverty U.S.A. http://www.nccbuscc.org/cchd/povertyusa

Video

What's Race Got to Do With It? written, directed, and produced by Jean Cheng; executive producer, Califomia Newsreel, Berkeley, CA: Califomia Newsreel, 2006

Skin Deөp, an Iris Films production, Berkeley, CA: Iris Films; San Francisco, CA: Califomia Newsreel, c1996

The Forgotten Americans, produced and directed by Hector Galán in association with Southwest Texas State University; executive producer, Jaime Chahin [San Marcos]: Southwest Texas State University, c2000

\section{Required Texts}

Adams M, Blumenfeld W, Castaneda R, Hackman $H$, Peters $M$, Zuniga $X$, eds. Reading for Diversity and Social Justice. New York, NY: Routledge; 2000.

Correspondents of the New York Times. Class Matters. New York, NY: Times Books; 2005.

Tatum BD. Why Are All the Black Kids Sitting Together in the Cafeteria? And Other Conversations on Race. New York: Basic Books; 2003. 